\title{
BRITISH SOCIETY FOR THE HISTORY OF PHARMACY
}

THIS NOTE on the British Society for the History of Pharmacy (BSHP) is occasioned by the Society's recent affiliation with the British Society of the History of Medicine.

The initiative for the formation of the BSHP in 1967 was taken by the History of Pharmacy Committee of the Pharmaceutical Society of Great Britain. After meeting for fifteen years the Committee felt that an independent Society, with non-restricted membership, would be more effective in promoting historical studies linked with pharmacy. It was, for instance, recognized that many local historians and historians of medicine and of science frequently met literary problems or antique objects requiring some pharmaceutical expertise.

The main policy of the BSHP since its inception has been to provide encouragement at provincial centres, it being felt that there was generally an adequate coverage in the London area by existing societies, which, though primarily concerned with medicine and science, commonly dealt with topics of pharmaceutical interest. It was appreciated that dividing lines between pharmaceutical, medical and scientific history were not always easy to draw, and the BSHP's own meetings have aimed at providing relevant background to pharmaceutical topics.

The successful annual, weekend residential meetings of BSHP have been on 'Pharmacy and Medicine in Wales' (at Cardiff), 'Medicine, Drugs and Population in the Eighteenth Century' (Nottingham), 'Pharmacy and Medicine in the Regency Period' (Bath) and 'Two Millenia of Pharmacy in the Newcastle Region' (Newcastle). A series of annual half-day meetings have also been held. The first (at Winchester) was on local history in Winchester, and the other three (at London and York) on pharmaceutical and medical antiques in ceramics, metal and glass. (The final meeting in this series, on wooden objects, is to be held at Birmingham later this year.) Other meetings held by the Society are half-day meetings at the annual British Pharmaceutical Conferences and occasional London evening meetings (up to two per year).

The Society has instituted two publications, a quarterly, printed newsletter, The Pharmaceutical Historian, and the Society's Transactions. The latter is an occasional publication, for lengthy scholarly articles; one copy has appeared to date.

The Pharmaceutical Society of Great Britain have generously aided the BSHP with financial grants, but BSHP is currently undertaking a drive to increase its membership to over 300 in order to aid its publishing programme. Plans for its future programme include emphasis on local history through arranging meetings with archivists and through long-term research projects organized by some of BSHP's members. BSHP would be pleased to co-operate with other societies in this type of work.

Enquiries for membership and information can be had from Dr. J. K. Crellin, Hon. Sec., c/o 17 Bloomsbury Square, London, W.C.1. 